analysis has not been presented for the Helsinki mental hospital study, though the results of this also suggested that reduction of raised plasma cholesterol by a high polyunsaturated:saturated ratio diet was associated with a reduction in incidence of coronary heart disease. ${ }^{7}$ The consistency in the results of these trials is impressive.

A further encouraging aspect of the Lipid Research Clinics trial is that regression of coronary atheroma has recently been reported, even though the resolution of the techniques used is still not perfected. ${ }^{8}$ Several studies are now being undertaken to determine the effects of diets and drugs on regression of atheromatous lesions in the femoral artery, as these are easier to study. If it can be shown that parallel changes take place in the femoral and coronary arteries, then it is probably reasonable to assume that when a beneficial effect is shown in femoral arterial lesions similar changes should occur in coronary lesions.

There are those who will be quick to extrapolate the positive findings of the Lipid Research Clinics trial to people with lower concentrations of serum cholesterol and LDL cholesterol, and many others who will wish to infer that cholesterol lowering diets will have a similar beneficial effect. But we should be wary against overinterpretation in either of these directions. The results of the trial apply only to the top 5\% at risk and, as the authors state, the trial was not designed to test the dietary hypothesis. So far, multiple risk factor intervention trials which have included cholesterol lowering diets have generally been unsuccessful, possibly because in these trials the amount by which the concentration of cholesterol was lowered was less and the motivation to observe a fairly stringent diet less. ${ }^{9}$ But the consistency in the results of all the primary prevention trials now suggests that at least those in the top quintile for plasma cholesterol should receive a diet with a high polyunsaturated:saturated ratio, perhaps with cholestyramine. The regimen must be sufficient to lower the plasma concentration of cholesterol over many years by about $10 \%$ and LDL cholesterol by $15 \%$. This requires a high degree of compliance; but if the need is explained adequately to people at high risk their motivation should be adequate.

There will also be others who will take encouragement and interpret the results in favour of the use of other cholesterol lowering drugs to prevent coronary heart disease. With the experience of the World Health Organisation clofibrate trial (which showed an increase in non-cardiovascular mortality) still fresh, however, the authors are surely right to state that "the mode of action, cholesterol lowering potency and possible toxicity of cholesterol lowering drugs must be taken into account before their use is advocated." The risk of correcting risk by drugs may be greater than the uncorrected risk. ${ }^{10}$

A far bigger effort is now needed to identify people with very high plasma cholesterol concentrations. There are three simple lines of approach which are more economic and practical methods of screening than that of taking blood from every man over 30 , particularly when only one in 20 will be affected. One is for hospital doctors to be assiduous in measuring plasma cholesterol (and, if high, LDL and HDL cholesterol) in all patients who develop angina or myocardial infarction under the age of 50 or 55 in order to identify high risk families; another is for cardiologists to liaise more closely with dermatologists, who not infrequently see patients with hypercholesterolaemic xanthomatosis; and a third is for family doctors to think hard about families where vascular disease has occurred prematurely or in excess and to screen all relatives for hypercholesterolaemia.

These trials of the effects of lowering cholesterol on coronary heart disease in high risk people have been tests of endurance for the participants, the architects, the investigators, and the analysts. Their perseverance has paid off, and patients with very considerable hypercholesterolaemia, particularly the young, should now be treated more vigorously. The fact that their poor prognosis may be changed is an important advance and should focus even more attention on the high risk strategy. ${ }^{9}$ But it should not be forgotten that the successful Lipid Research Clinics study was a trial using a gastrointestinal resin and not a diet trial and that it was limited to those in the top $5 \%$ of plasma cholesterol distribution.

Duke of Edinburgh Professor of Cardiology,

M F OLIVER

University of Edinburgh,

Cardiovascular Research Unit,

Edinburgh EH8 9XF

1 Anonymous. The Lipid Research Clinics coronary primary prevention trial results. I. Reduction in incidence of coronary heart disease. $\mathcal{F} A M A$ 1984;251 :351-64.

2 Anonymous. The coronary primary prevention trial: design and implementation. F Chronic Dis 1979;31:609-31.

${ }^{3}$ Anonymous. The Lipid Research Clinics coronary primary prevention trial results. II. The relationship of reduction in incidence of coronary heart disease to cholesterol lowering. fAMA 1984;251:365-74.

${ }^{4}$ Hjermann I, Byre KV, Holme I, Leren P. Effect of diet and smoking intervention on the incidence of coronary heart disease. Report from the Oslo study group of a randomized trial in healthy men. Lancet 1981 ;ii: 1303-10.

5 WHO Clofibrate Trial Committee of Principal Investigators. A co-operative trial in the primary prevention of ischaemic heart disease using clofibrate. Br Heart f 1978;40:1069-118.

${ }^{6}$ Dayton S, Pearce ML, Hashimoto S, et al. A controlled clinical trial of a diet high in unsaturated fat in preventing complications of atherosclerosis. Circulation 1969;40, suppl 2:1-63.

7 Turpeinen O, Karvonen MJ, Pekkarinen M, et al. Dietary prevention of coronary heart disease: the Finnish mental hospital study. Int $\mathcal{f}$ Epidemiol 1979;8:99-118.

${ }^{8}$ Levy RI. The influence of cholestyramine-induced lipid changes on coronary artery disease progression: the NHLBI type II coronary intervention study. (Abstract.) Arteriosclerosis 1983;3:481a.

9 Oliver MF. Should we not forget about mass control of coronary risk factors ? Lancet 1983;ii:37-8.

${ }^{10}$ Oliver MF. Risks of correcting the risks of coronary disease and stroke with drugs. $N$ Engl f Med $1982 ; 306: 297-8$.

\section{Smoking in pregnancy}

Most adults in Britain are now non-smokers, ${ }^{1}$ and this is true in all social classes. From 1972 to 1982 the proportion of men who were heavy smokers (20 or more cigarettes a day) decreased, but no such change has been seen in women who smoke heavily (who are mostly in social class V). The consequences of this differential flight from cigarettes by heavy smokers affects not only these women but their children.

The complex effects of smoking on pregnancy and its outcome have recently been examined by Sidle in a review of 336 papers on this topic. ${ }^{2}$ Concentrating on the relations between smoking and birth weight, perinatal mortality, and prematurity he has also examined the effects of smoking during pregnancy on handicap, pre-eclampsia, spontaneous abortion, and congenital abnormalities-as well as the different effects of carbon monoxide, cyanide, and new types of cigarette. The long term effects on the child after birth have been similarly reviewed.

As early as 1902 Ballantyne had found an increase in the abortion rate in French and Austrian women working in tobacco factories. In 1929 Knopf suggested that smoking itself might adversely affect the developing child, but interest in the subject was limited until the early 1970 s, when several studies showed an association between maternal smoking and reduced birth weight as a result of retardation of fetal intrauterine growth. ${ }^{3}$ Chronic fetal deficiency of oxygen was considered to be the result of 
placental insufficiency caused by vasoconstriction due to nicotine and high carboxyhaemoglobin concentrations in fetal and maternal blood. ${ }^{4} \mathrm{~A}$ case-control study which examined blood at birth from 40 infants whose mothers smoked 20 cigarettes a day, and from 40 controls, found that maternal smoking during pregnancy resulted in a change of fetal blood viscosity (30\% increase), and the mean birth weight was $318 \mathrm{~g}$ lower than in the control group of infants. ${ }^{5}$ Wainright found that when non-smoking women began smoking between pregnancies the birth weights of their later children were on average $67 \mathrm{~g}$ less than those of non-smoking controls; while when 159 women who smoked stopped smoking before their next pregnancy their ensuing children averaged $169 \mathrm{~g}$ heavier than those of matched controls who continued smoking. ${ }^{6}$ The results of that study clearly suggested that smoking rather than any hypothesised constitutional factor affected the development of the fetus. Martin's view of smoking during pregnancy concluded that it generally resulted in a $150-200 \mathrm{mg}$ reduction in weight and a $20 \%$ increase in the neonatal death rate among children born to women smoking less than a pack a day, and a $35 \%$ greater chance of neonatal death for those smoking more than a pack a day. ${ }^{7}$ A woman who smoked was $20 \%$ more likely to abort or to have bleeding and anaemia during pregnancy. Martin also noted that only $12-13 \%$ of women who smoked curtailed this habit during pregnancy.

The relation between maternal smoking and other factors is more complex, but there is now more evidence on its short term effects on the respiratory health of infants and young children. Both maternal and paternal smoking (that is, passive smoking or "sidestream") have been found to have an adverse effect on infants' respiratory health, with more children of smoking parents having bronchitis and pneumonia in the first year of life. ${ }^{8-10}$ Studies by Fergusson and colleagues in New Zealand suggested that the mother's smoking was more important than the father's. ${ }^{11-13}$

Young people drift into starting to smoke because they see it as adult behaviour enjoyed by family and friends. ${ }^{14}$ This quickly leads to dependence (or addiction) to nicotine. ${ }^{16}$ Giving up is not, however, impossible. Two thirds of American physicians once smoked but over two decades this dropped to one fifth. ${ }^{17} \mathrm{~A}$ recent review about alcohol and advice to pregnant women stated that the United States Surgeon General advised women who were pregnant "not to drink alcoholic beverages" and that the Royal College of Psychiatrists had recommended that "women would be well advised not to drink alcohol during pregnancy." 18 The premise of these two reports was not that moderate drinking carried dangers to the fetus but that the possibility of such dangers had to be entertained. Similar cautious, responsible advice about smoking should now be available for all young women of childbearing age. It would be irresponsible not to tell them that smoking may damage both their own health and that of their unborn child, but this information needs to be given sensitively. If a woman is unable to stop smoking, strong exhortations for her to desist because she is damaging her unborn child's health might cause feelings of guilt and inadequacy without achieving anything.

Doctors should make more effort to dissuade pregnant women from smoking. A survey in a maternity department showed that $32 \%$ of those who were smokers when they became pregnant claimed that no medical adviser had attempted to dissuade them. ${ }^{19}$ More of the mothers who gave up smoking in early pregnancy admitted to a knowledge of possible hazards to the fetus than those who smoked continuously throughout pregnancy. The proportions admitting knowledge of the damages to the fetus and to themselves were higher among those who acknowledged receiving advice from their medical advisers. The poster campaign instituted by the Health Education Council had had no significant effect. ${ }^{19}$

The pregnant woman who smokes heavily is more than twice as likely as a non-smoker to lose her baby at or near birth ${ }^{20}$ but this factor is smaller than the five times greater likelihood she faces of developing lung cancer compared with a nonsmoker. ${ }^{21}$ Nevertheless, smoking does pose a special problem for women. From time immemorial different standards of behaviour have been expected from the two sexes. This has included sexual behaviours, the use of alcohol and tobacco, receiving lower pay for similar work, and in general accepting a secondary role. Supporters of women's emancipation naturally demand an equality that includes adopting the sins and vices of men. It is therefore hard to have to point out that smoking entails extra risks for those who may bear children. Some cigarette advertising, in the form of "sponsorship," appears to be specifically aimed at young women..$^{22}$ The winner of the women's singles at Wimbledon started tie tennis championships sporting the colours of the cigarette Kim. ${ }^{23}{ }^{24}$ "You've come a long way Baby!" as the advertisement for "Virginia Slims" says, but the baby could have been bigger and fitter if the mother had not been affected by such advertisements. The smoking epidemic is clearly beginning to decline, though there is still a long way to go. In 100 years' time the arguments of those promoting smoking, and smokers' freedom, will be seen to be as retrograde and foolish as the arguments of those who once sought to postpone the abolition of slavery, or delay the development of underground pipes for sewage (rather than continue to allow it to run in the streets). Reason eventually prevailed and doubtless will do so also with smoking. Promotion by tobacco companies may then be seen for what it is-the "pushing" of a dangerous drug.

BeULAH R BEWLeY

Senior Lecturer,

Department of Community Health,

London School of Hygiene and Tropical Medicine,

London WC1E 7HT

${ }^{1}$ Office of Population Censuses and Surveys. Cigarette smoking 1972-1982. London: Office of Population Censuses and Surveys, 1983. (OPCS Monitor GHS 83/3.)

${ }^{2}$ Sidle N. Smoking and pregnancy-a review. London: Hera Unit, The Spastics Society, 1982.

${ }^{3}$ Howie PW. Causes of intrauterine growth retardation. $\mathrm{Br}$ Med $\mathcal{F} 1982$; 285:156-7.

4 Pirani BBK. Smoking in pregnancy. Obstet Gynecol Surv 1978;33:1-13.

${ }^{5}$ Buchan PC. Cigarette smoking in pregnancy and fetal hyperviscosity. Br Med f 1983;286:1315.

6 Wainright RL. Change in observed birth weight associated with change in maternal cigarette smoking. Am F Epidemiol 1983;117:668-75.

${ }^{7}$ Martin JC. An overview: maternal nicotine and caffeine consumption and offspring outcome. Neurobehav Toxicol Teratol 1982;4:421-7.

${ }^{8}$ Harlap S, Davies AM. Infant admissions to hospital and maternal smoking. Lancet 1974 ; i :529-32.

${ }^{9}$ Colley JRT, Holland WW, Corkhill RT. Influence of passive smoking and parental phlegm on pneumonia and bronchitis in early childhood. Lancet 1974 ;ii:1031-4.

${ }^{10}$ Leeder SR, Corkhill R, Irwig LM, Holland WW, Colley JRT. Influence of family factors on the incidence of lower respiratory illness during the first year of life. British fournal of Preventive and Social Medicine $1976 ; 30: 203-12$.

${ }^{11}$ Fergusson DM, Horwood LJ, Shannon FT. Parental smoking and respiratory illness in infancy. Arch Dis Child 1980;55:358-61.

12 Fergusson DM, Horwood LJ, Shannon FT, Taylor B. Breast-feeding, gastrointestinal and lower respiratory illness in the first two years. Aust Paediatr 7 1981;17:191-5.

${ }^{13}$ Fergusson DM, Horwood LJ, Shannon FT, Taylor B. Parental smoking and lower respiratory illness in the first three years of life. $\mathcal{I}$ Epidemiol Community Health $1981 ; 35: 180-4$.

${ }^{14}$ Bynner JM. The young smoker. London: HMSO, 1969.

15 Bewley BR, Bland JM, Harris R. Factors associated with the starting of cigarette smoking by primary school children. British fournal of Preventive and Social Medicine $1974 ; 28: 37-44$.

${ }^{16}$ Ashton H, Stepney R. Smoking, psychology and pharmacology. London: Tavistock Publications, 1982. 
$17 \mathrm{Jaffe} \mathrm{JH}$. Cigarette smoking as an addiction. American Lung Association Bulletin 1976; May:10-2.

18 Edwards G. Alcohol and advice to the pregnant woman. $B r$ Med $\mathcal{F} 1983$; 286 :247-8.

19 Dalton ER, Hughes CA, Cogswell JJ. Cigarette smoking in pregnancy: a health education problem. Public Health 1981 ;95:207-14.

20 Surgeon General. The health consequences of smoking for women. Washington, DC: US Department of Health Education and Welfare, 1980: 211-4.

${ }^{21}$ Jacobson B. The ladykillers: why smoking is a feminist issue. London: Pluto Press, 1981:73.

22 Jacobson B. Smoking and health: a new generation of campaigners. $\mathrm{Br}$ Med f 1983;287:483-4.

${ }^{23}$ Anonymous. Navratilova's outfit angers non-smokers. Guardian 1983 Jun $27: 4$ (cols 7,8 ).

24 Anonymous. Navratilova shirt row. Guardian 1983 June 28:5 (col 2).

\section{Analogues of gonadotrophin releasing hormone}

In 1960 McCann et al showed that a hypothalamic extract caused the release of luteinising hormone from the pituitary. ${ }^{1}$ Luteinising hormone releasing hormone (LHRH) was identified as a decapeptide in 1971 by Schally et $a l^{2}$ and since the purified peptide was found to release both luteinising hormone and follicle stimulating hormone it was renamed gonadotrophin releasing hormone. Several analogues of gonadotrophin releasing hormone were synthesised in the hope of finding one with higher activity. ${ }^{3}$ These differed from the parent molecule by having amino acids substituted in varying positions, those analogues with substitutions at the sixth and 10th positions being described as "superactive" because a single injection led to supraphysiological increases in the pituitary gonadotrophins. ${ }^{4}$

At first the superactive analogues were expected to be effective in inducing puberty in patients with hypogonadism. No such effect was observed, however ${ }^{5}$; indeed, their repeated administration to animals actually resulted in a decrease in gonadotrophins and gonadal hormones with a regression of secondary sexual characteristics. ${ }^{6}$ This paradoxical effect of the long term administration of the "superactive" gonadotrophin releasing hormone analogues is explained because the normal mechanism depends on a response by the pituitary to the pulsatile release of endogenous gonadotrophin releasing hormone. ${ }^{7}$ The superactive analogues bind for prolonged periods to the pituitary receptors for gonadotrophin releasing hormone, rendering them unresponsive, ${ }^{8}$ so that after an initial stimulation the system becomes blocked with decreased secretion of the pituitary gonadotrophins and ultimately of the gonadal hormones. ${ }^{9} 10$ In addition, the superactive analogues may have a direct effect on the ovary and testis. ${ }^{112}$ Against initial expectations, the function of the superactive analogues, now renamed "long acting," has turned out to be in conditions where gonadal activity needs to be suppressed rather than stimulated.

Initially long acting gonadotrophin releasing hormone analogues were investigated as possibly safer alternatives to contraceptives containing oestrogen. In Scandinavia Nilius, Bergquist, and Wide pioneered the assessment of $D-\operatorname{Ser}\left(B^{t}\right)^{6}$ LHRH ethylamide (buserelin) and succeeded in establishing an intranasal dosage regimen effective in suppressing ovulation in 24 of 26 women treated with between 400 and $600 \mu \mathrm{g}$ daily. ${ }^{10}$ Linde et al then studied the antifertility effects in men of D-Trp ${ }^{6}$ Pro $^{9}$ LHRH ethylamide, finding decreases in sperm counts in all eight of the subjects; in six the counts were lowered to below $6 \times 10^{6}$ sperms $/ \mathrm{ml}^{13}$ Although the men became impotent with treatment, depot testosterone supplements might overcome this side effect and allow the analogues to be used as male contraceptives.

In the late 1970s further applications of the long acting gonadotrophin releasing hormone analogues began to be recognised, and Crowley et al successfully treated a girl with idiopathic precocious puberty. ${ }^{14}$ Subsequently both girls and boys have been treated for this condition. With the long term use of these compounds, however, a relative resistance to treatment has been seen in girls but not in boys (C G D Brook, personal communication). The long acting analogues have been used in other conditions where gonadal "down regulation" is wanted, and in both endometriosis ${ }^{15}$ and idiopathic oedema (J A H Wass, personal communication) effective treatment has led to objective improvement. The D-Ser ${ }^{6}$ substituted analogue given intranasally has been used as an alternative treatment for severe acne. ${ }^{16}$

Possibly the most important future application of this group of compounds is in the management of sex hormone dependent cancers. Their most obvious use is in prostatic cancer, the fourth most common tumour of men. This is known to be responsive to hormones, but no treatment has been shown to prolong survival. ${ }^{17}$ All current treatments have disadvantages, and some may actually affect survival adversely; thus conventional dosages of diethylstilboestrol result in an excess of deaths from cardiovascular causes. ${ }^{18}$ After the initial description in 1982 of the regression of canine prostatic cancer with Nac- $p$-C1-D-Phe ${ }^{1,}$,, D-Trp ${ }^{3}$, D-Phe ${ }^{6}$, D-Ala ${ }^{10}$ LHRH $^{19}$ several reports appeared of the early results of the treatment of human carcinoma of the prostate. ${ }^{20-24}$ In these five studies 42 of 52 patients responded to treatment. We now need to know whether the analogues are as effective in the long term control of the disease as orchidectomy, and this point is being investigated in a randomised trial.

Klijn and de Jong reported the successful treatment with buserelin of two of four premenopausal patients with cancer of the breast. ${ }^{25}$ The advantages of the use of gonadotrophin releasing hormone analogues in premenopausal patients with breast cancer are not as apparent as in prostatic cancer. This is because the number of premenopausal women with breast cancer is limited and most patients prefer to undergo laparoscopic oophorectomy-so much so that a recent American trial of the arginine substituted analogue was not completed. The long acting analogues of gonadotrophin releasing hormone are, however, also being evaluated in postmenopausal women with breast cancer. If these compounds are confirmed to be effective further light might be cast on the mechanisms of response to hormones in breast cancer.

Long acting gonadotrophin releasing hormone analogues have not yet been investigated in other hormone related cancers but warrant investigation in patients with ovarian, endometrial, and possibly renal tumours. As well as being used in primary treatment the analogues may have a possible adjuvant function in preserving the fertility of young patients treated for curable cancers and lymphomas with sterilising cytotoxic chemotherapy. This possible use of the long acting analogues in Hodgkin's disease is being investigated at St Bartholomew's and the Christie Hospitals in a study that began in 1981 .

Long acting gonadotrophin releasing hormone analogues have disadvantages in terms of ease of administration. These disadvantages are being overcome, and depot preparations are being developed by ICI and Hoechst. This class of compounds is of profound medical importance and the possible therapeutic 